\title{
Side-Effects of Public Health Policies Against Covid-19: The Story of an Over-Reaction
}

\author{
Edouard Lansiaux ${ }^{1 *}$, Noé Tchagaspanian $^{1}$, Juliette Arnaud ${ }^{1,2}$, Pierre Durand ${ }^{1}$, \\ Mark Changizi ${ }^{3}$ and Joachim Forget ${ }^{1,4}$ \\ ${ }^{1}$ Global Variations, Genève, Switzerland, ${ }^{2}$ Ecole Normale Supérieure, Paris, France, ${ }^{3}$ Human Factory, Columbus, OH, \\ United States, ${ }^{4}$ Assemblée Nationale, Paris, France
}

Keywords: COVID-19, lockdown, curfew, mask, side-effects, health policy, public health, non-pharmaceutical intervention

\section{INTRODUCTION}

The world has been facing a coronavirus disease (COVID-19) pandemic since November 2019. While there may have been a short period at the start when the risk of the pandemic was underestimated, by February and March of 2020, the Western world reacted in earnest with varieties of non-pharmaceutical interventions. However, the overall effects of those interventions had not at that point been sufficiently studied, and in many cases what existing literature existed did not recommend them. Furthermore, beyond the issue of whether the interventions were narrowly effective, there is the issue of their potential side effects on global health, something that was given surprisingly little attention.

The medical motto "primum non nocere" (《first, do not harm》), a moral principle everyone should at least consider following, was evidently not observed. The potential up sides of the interventions were promoted and communicated, but rarely the myriad possible down sides. This opinion article highlights a variety of the down sides in an effort to emphasize the broad range of complex issues that must be balanced when governments enact policy.

Linda L. Benskin,

Independent Researcher, Austin,

United States

*Correspondence:

Edouard Lansiaux

edouard.lansiaux@globalvariations.com

Specialty section:

This article was submitted to

Public Mental Health,

a section of the journal

Frontiers in Public Health

Received: 28 April 2021

Accepted: 24 May 2021

Published: 13 September 2021

Citation:

Lansiaux E, Tchagaspanian N, Arnaud J, Durand P, Changizi $M$ and Forget J (2021) Side-Effects of Public Health Policies Against Covid-19: The

Story of an Over-Reaction.

Front. Public Health 9:696818. doi: 10.3389/fpubh.2021.696818

\section{LOCKDOWNS}

\section{Epidemiological Effects}

In the Middle Ages, before the discovery of pathogen vectors, patients were seen as presenting a health and social risk. Since then, "detect, isolate, treat" has almost always been, and still is, the credo. Isolation used to be selective. For example, there were lazarettos that were used to keep ship passengers or patients in quarantine (1). In seventeenth century London, only infected families were "shut-up" in their homes, their doors being marked with red crosses (2) in order to prevent other people from paying them visits. A general lockdown extending to healthy or asymptomatic people was very uncommon, almost without historical precedent, and lacking scientific basis.

Stay-at-home mandates' impact on mortality is subject to debate, for while some studies report its epidemiological impact (3), many others suggest an absence of COVID-19 mortality reduction due to the lockdown $(4,5)$. Moreover, the comparison of pre- and post- lockdown observations reveals a counter-intuitive slowdown in the decay of the epidemic after lockdown $(6,7)$. In a nutshell, many studies now suggest lockdown inefficacy for COVID-19 mortality, and even sometimes SARS-CoV-2 mere transmission $(8,9)$. A Stanford epidemiological study (10) did not find significant benefits on case growth of more restrictive non-pharmaceutical interventions (NPIs).

More important for our purposes here, though, are the side effects, and epidemiologically there is considerable evidence now of significant increased mortality due to lockdowns and the 
connected changes to medical practice that occurred during the pandemic. For example, according to a Centers for Disease Control and prevention (CDC) report (11) concerning excess deaths in the US between January 26th 2020 and October 3rd $2020,1 / 3$ of them (or 100,000) were not COVID-19-related (12). It is beyond the scope of this short piece to review the literature on these lockdown-related deaths, but it is crucial to note that the important comparison is not the number of lockdownrelated deaths to the number of COVID-19-related deaths, but, rather, the number of lockdown-related deaths to the number of COVID-19 deaths averted by virtue of the interventions.

According to a study conducted by the National Bureau of Economic Research (13), for the overall US population, the proportion of COVID-19 related unemployment is today between two and five times larger than the typical unemployment shock, resulting in a $3.0 \%$ increase in mortality rate and a $0.5 \%$ drop in life expectancy over the next 15 years. Deaths from drug and alcohol misuse also significantly increased during the lockdown period in comparison to the same period in 2018 (14). The damage to the economy by lockdowns will cost many years of life-and poverty is a silent killer (15).

Lockdowns are far from being a magic spell that can save the world from a pandemic: They might not even narrowly work to lower mortality, and appear to lead to their own share of non-COVID-19 deaths (16).

\section{Psychological Side-Effects}

During this COVID-19 period, economic vulnerability was associated with a strong risk of stress and worsening mental health (17). According to Sonia Mukhtar, lockdowns, whose consequences are self-isolation quarantine and social distancing, constituted collective traumatic events that are perceived by people as serious threats, and have already resulted in a considerable loss of life and in an impoverishment of global hygiene (18). Indeed, as Mingke Song assessed for China, COVID-19 and lockdown policies not only brought upon a life crisis, but also incurred psychological stress: tension, anxiety, fear and despair among affected populations (19). A review also found that some factors increasing women's vulnerabilities to violence have been exacerbated during the lockdown period (20).

The psychological effects of isolation in non-epidemic situations have already been studied in specific cases, such as that of imprisonment $(21,22)$. Not everyone is able to be as positive and creative as Xavier de Maistre was when he wrote his impressive Voyage autour de ma chambre during his imprisonment in Turin, in 1794.

Previous epidemics and the specific lockdowns they caused also had psychological effects, and were described by specialists $(23,24)$. The risk of PTSD (post-traumatic stress disorder) symptoms is at its highest, even after some time, and even after home quarantine.

Lockdowns led to most medical care being done via cybervisits, which greatly reduces the physician's ability to perceive health signs. Doctors are often not even consciously aware of their fine-tuned perceptual abilities. For example, our variety of color vision evolved so as to sense oxygenation modulations under the skin (for recognition of emotion, health and state) (25), and it has been recognized since the Greeks that the acute pallor of the skin is helpful for diagnosis (26). These blood-mediated health signals are only visible in person, not through cameras.

\section{Physiological Effects}

Lockdowns also increase the duration of time for which people are sedentary, which has a variety of harmful side effects including: altered energy expenditure, adipogenic signaling, immunomodulation, autonomic stability, and hormonal dysregulation perpetuating underlying chronic diseases such as obesity, cardiovascular disease, cancer and mental health disorders, which are grave physiological effects (27). In addition, Digital Eye Syndrome (user's visual system regulation difficulty mainly caused by an overuse of digital devices) may have been exacerbated precisely because of lockdowns (28).

\section{MASKS}

\section{Effectiveness}

The debate regarding the effectiveness of masks is still ongoing. Indeed, some believe masks are ineffective (for both this coronavirus virus and influenza variants) (29-31), others defend the simple surgical mask efficiency (this is the most common scientific opinion), and others are calling for more effective masks (32).

Even supposing face masks might provide some measure of protection, there are side effects that could undermine any efficacy they may have. First, wearing a mask may give a false sense of security and make people less compliant with social distancing, ventilation and other important infection control schemes $(33,34)$. Second, people have to avoid touching their masks and adopt other management measures, otherwise masks may be counterproductive (35).

While face masks can stop larger droplets, such droplets tend to fall to the ground due to their weight (36-38), and are not the route for viral transmission. Viruses spread via smoke-like aerosols (39) via breath (or flatulence), which go through and jet out the sides of surgical masks, and infect mainly by inhalation deep into the lungs. Despite the risk of inhaling/exhaling infected virions via leaks of particles, this was never evaluated in applied norms for surgical masks, and only for Personal Protective Equipment (PPE) under the Filtering Facepiece Particles (FFP) norm in Europe, and N (e.g., N95) in the USA. Moreover, the European norm for surgical masks (EN14683) as well as the US (ASTM) only applies to Bacterial Filtration Efficiency (BFE), and the size of the bacteria used for testing ( 3 microns) is much larger than the SARS-CoV-2 [maximum size of $140 \mathrm{~nm}(40)$ ]. Virus filtration efficiency (VFE) was never tested in Chinese and European norms.

\section{Psychomotor Effects}

Mask-wearing could affect infants' and children's psychomotor development, as well as facial recognition (41). The stillface effect (42), for example, illustrates the human grasp of emotional expressions from very early in life, something obviously interrupted in a world filled with masked people. 
Moreover, one could speculate that because brain areas in the left fusiform cortex were recycled for reading expertise (43), while face recognition expertise is more lateralized in the homolateral fusiform cortex (44), some upcoming dyslexic syndromes could be expected as a consequence of the lack of face visual recognition skills' development due to bilateral ventral stream impairment.

Masks also block vision of one's lower far peripheral visual field, which is crucial for visuomotor feedback when engaged in walking (45-48), something almost never consciously realized (49). Falls are a major public health concern because falls are the second leading cause of accidental or unintentional injury deaths worldwide-each year approximately 650,000 individuals die from falls (50).

\section{Psychological Effects}

Masks severely handicap us in our most fundamental way of communicating-our emotional expressions (51-53), something that is as relevant in health diagnoses (54) as it is in regular life. For instance, a randomized clinical trial has shown that health care professionals wearing masks have a significant and negative impact on the patient's perceived empathy and diminish positive effects of relational continuity (55).

A recent study also showed that each type of mask caused a low-pass filter effect, attenuating higher frequencies $(2,000-$ $7,000 \mathrm{~Hz}$ ) in the speaker's voice by $3-4 \mathrm{~dB}$ (medical mask) and nearly $12 \mathrm{~dB}$ for the N95 mask (respirator/FFP) (56). In addition to this, masks significantly prevent binding mechanisms through which de-synchronized auditory and motor signals from language are usually fused into conscious workspace-a phenomenon known as the McGurk effect (57).

Also, a review notably supports the idea that panic-prone individuals may be at higher risk of respiratory discomfort when wearing RPDs, thereby reducing their tolerance for these devices (58).

\section{Dermatological Effects}

Many studies have described the dermatological impact of prolonged mask wearing. Mask wearing induces itches (59) and contact dermatitis (60). The most common adverse skin reactions among healthcare workers wearing N95 masks have been nasal bridge scarring (68.9\%) and facial itching (27.9\%) (61), nasal bridge, cheeks and chin (35.5\%) (62). N95 respirators are associated with more skin reactions than medical masks (63), and skin tears and open wounds such as these are a themselves potential source of infection (64). Last but not least, the current form of fluid resistant surgical masks (FRSM) used in day-to-day practice has elastic ties that go behind the ears, and an extended use of these masks causes discomfort and irritation behind them, especially if they are used for prolonged procedures (65).

\section{REFERENCES}

1. Devaux C. Small oversights that led to the great plague of marseille (1720-1723): lessons from the past. Infect Genet Evol. (2012) 14:169-85. doi: 10.1016/j.meegid.2012. 11.016

\section{Physiological Effects}

This first randomized cross-over study concerning the effects of surgical masks and FFP2/N95 masks on cardiopulmonary exercise capacity yields clear results: both varieties of mask have a marked negative impact on exercise parameters (66). Furthermore, a German MD thesis (67) showed that the usage of a face mask leads to: increased rebreathing of expelled carbon dioxide; significant increased respiratory rate and hyperventilation; increased heart rate; increase in $\mathrm{CO}_{2}$ in the blood; hypoxemia, which is an abnormal decrease in the partial pressure of oxygen in the arterial blood; hypercapnia, which is an increase in the pressure of $\mathrm{CO}_{2}$ in the blood. To sum up, as WHO claimed in August 2020: "People should not wear masks when exercising, as masks may reduce the ability to breathe comfortably" (68).

A final consequence of universal mask wearing worth mentioning is one at the societal level: once an unmasked face becomes verboten in most public circumstances, it can end up psychologically treated as a "private part" that must be covered, like all our private parts, something that can be difficult to undo.

\section{CONCLUSION}

Our opinion article highlighted just some of the many side effects of NPIs that have been adopted by our governments since the COVID-19 crisis began. Even in a terrible epidemic, decisions cannot be taken without an exhaustive risk-benefit analysis, not to mention consideration of civil liberties.

Other potential directions for government responses include policies encouraging better ventilated indoor spaces, "test, trace, isolate" (on a specific scale and not a globalized one) as it was applied in Asian countries, mass vaccinations, and early treatments [although none is actually proven as effective yet, such as the ACEi/ARBs example (69)].

The responses of governments need to be guided by scientific decision-making algorithm (70) and when this dialogue between public authorities and scientists exist, it allows superior pandemic management (71).

\section{AUTHOR CONTRIBUTIONS}

MC and JF designed the research. EL and NT conducted the research and wrote the first draft of the manuscript. EL, NT, JA, $\mathrm{PD}, \mathrm{MC}$, and JF contributed to the writing of the manuscript. All authors contributed to the data interpretation, revised each draft for important intellectual content, and read and approved the final manuscript. 
4. Chaudhry R, Dranitsaris G, Mubashir T, Bartoszko J, Riazi S. A country level analysis measuring the impact of government actions, country preparedness and socioeconomic factors on COVID-19 mortality and related health outcomes. EClinicalMedicine. (2020) 25:100464. doi: 10.1016/j.eclinm.2020.100464

5. Larochelambert Q, Marc A, Antero-Jacquemin J, Bourg E, Toussaint JF. Covid-19 mortality: a matter of vulnerability among nations facing limited margins of adaptation. (2020) Front Public Health. 8:604339. doi: 10.3389/fpubh.2020.604339

6. Meunier T. Full lockdown policies in western Europe countries have no evident impacts on the COVID-19 epidemic. meRrxiv. (2020) doi: 10.1101/2020.04.24.20078717

7. Edouard Lansiaux, Jean-Luc Caut, Joachim Forget et al. Assessing the Efficiency of COVID-19 NPIs in France: A Retrospective Study Using a Novel Methodology. (2021). Research Square.

8. Atkeson A, Kopecky K, Zha T. Four Stylized Facts About COVID-19 [Internet]. Cambridge, MA: National Bureau of Economic Research (2020).

9. Cao S, Gan Y, Wang C, Bachmann M, Wei S, Gong J, et al. Post-lockdown SARS-CoV-2 nucleic acid screening in nearly ten million residents of Wuhan, China. Nat Commun. (2020) 11:5917. doi: 10.1038/s41467-020-19802-w

10. Bendavid E, Oh C, Bhattacharya J, Ioannidis J. Assessing mandatory stay-athome and business closure effects on the spread of COVID-19. Eur J Clin Invest. (2021) 51:e13484. doi: 10.2139/ssrn.3746254

11. Rossen LM, Branum AM, Ahmad FB, Sutton P, Anderson RN. Excess deaths associated with COVID-19, by age and race and ethnicity-United States, January 26-October 3, 2020. Morb Mortal Wkly Rep. (2020). 69:1522-7. doi: $10.15585 / \mathrm{mmwr.mm6942 \textrm {e } 2}$

12. Rabin RC. The Pandemic's Real Toll? 300,000 Deaths, and It's Not Just From the Coronavirus. New York Times. (2020). Available online at: https://www. nytimes.com/2020/10/20/health/coronavirus-excess-deaths.html?fbclid= IwAR24gC-86qZv23Hd7Vc_xiYLDmu6PzqWUzAIUy72NMAXyDJMViIpTZ0pvQ.

13. Bianchi F, Bianchi G, Song D. The Long-Term Impact of the COVID-19 Unemployment Shock on Life Expectancy and Mortality Rates [Internet]. National Bureau of Economic Research. (2020) (Working Paper Series). Report No.: 28304. Available online at: http://www.nber.org/papers/w28304. doi: 10.3386/w28304

14. Pell R, Fryer E, Manek S, Winter L, Roberts I. Coronial autopsies identify the indirect effects of COVID-19. Lancet Public Health. (2020) 5:e474. doi: 10.1016/S2468-2667(20)30180-8

15. Evans M. Hospitals Retreat From Early Covid Treatment and Return to Basics. The Wall Street Journal. (2020). Available online at: https://www.wsj.com/ articles/hospitals-retreat-from-early-covid-treatment-and-return-to-basics11608491436.

16. Rancourt D, Baudin M, Mercier J. Evaluation of the virulence of SARSCoV-2 in France, from all-cause mortality 1946-2020. ResearchGate. (2020). doi: 10.13140/RG.2.2.16836.65920/1

17. Codagnone C, Id F, Mez C, Charris R, Montealegre F, Liva G, et al. Assessing concerns for the economic consequence of the COVID-19 response and mental health problems associated with economic vulnerability and negative economic shock in Italy, Spain, and the United Kingdom. PLoS ONE. (2020) 15:e0240876. doi: 10.31235/osf.io/x9m36

18. Mukhtar S. Mental health and psychosocial aspects of coronavirus outbreak in pakistan: psychological intervention for public mental health crisis. Asian J Psychiatry. (2020) 51:102069. doi: 10.1016/j.ajp.2020.102069

19. Song M. Psychological stress responses to COVID-19 and adaptive strategies in China. World Dev. (2020) 136:105107. doi: 10.1016/j.worlddev.2020.105107

20. Sánchez O, Vale D, Rodrigues L, Surita F. Violence against women during the COVID-19 pandemic: an integrative review. Int J Gynecol Obstet. (2020) 151:180-7. doi: 10.1002/ijgo.13365

21. Combalbert N, Pennequin V, Ferrand C, Lenormand M, Anselme M, Geffray B. Cognitive impairment, self-perceived health and quality of life of older prisoners. Crim Behav Mental Health. (2018) 28:36-49. doi: 10.1002/ cbm.2023

22. von Werthern M, Robjant K, Chui Z, Schon R, Ottisova L, Mason C, et al. The impact of immigration detention on mental health: a systematic review. BMC Psychiatry. (2018) 18:382. doi: 10.1186/s12888-018-1945-y
23. Lee S, Kang W, Cho A-R, Kim T, Park J. Psychological impact of the (2015). MERS outbreak on hospital workers and quarantined hemodialysis patients. Compr Psychiatry. (2018) 87:123-7. doi: 10.1016/j.comppsych.2018.10.003

24. Taylor M, Agho K, Stevens G, Raphael B. Factors influencing psychological distress during a disease epidemic: data from Australia’s first outbreak of equine influenza. BMC Public Health. (2008) 8:347. doi: $10.1186 / 1471-2458-8-347$

25. Changizi M, Zhang Q, Shimojo S. Bare skin, blood and the evolution of primate colour vision. Biol Lett. (2006) 2:217-21. doi: 10.1098/rsbl.2006.0440

26. Changizi $M$, Rio $K$. Harnessing color vision for visual oximetry in central cyanosis. Med Hypotheses. (2009) 74:87-91. doi: 10.1016/j.mehy.2009.07.045

27. Chandrasekaran B, Ganesan T. Sedentarism and chronic disease risk in COVID 19 lockdown-a scoping review. Scott Med J. (2020) 66:3-10. doi: $10.1177 / 0036933020946336$

28. Munsamy A, Chetty V. Digital eye syndrome-COVID 19 LOCKDOWN side effect? South Afr Med J. (2020) 110:12978. doi: 10.7196/SAMJ.2020.v110i7.14906

29. Bundgaard H, Bundgaard JS, Raaschou-Pedersen DET, von Buchwald C, Todsen T, Norsk JB, et al. Effectiveness of adding a mask recommendation to other public health measures to prevent SARS-CoV-2 infection in Danish mask wearers. A randomized controlled trial. Ann Intern Med. (2020) 174:335-43. doi: 10.7326/M20-6817

30. Matuschek C, Moll F, Fangerau H, Fischer J, Zänker K, van Griensven M, et al. Face masks: Benefits and risks during the COVID-19 crisis. Eur J Med Res. (2020) 25:32. doi: 10.1186/s40001-020-00430-5

31. Xiao J, Shiu E, Gao H, Wong JY, Fong MW, Ryu S, et al. Nonpharmaceutical measures for pandemic influenza in nonhealthcare settings-personal protective and environmental measures. Emerg Infect Dis. (2020) 26:967-75. doi: 10.3201/eid2605.190994

32. Kollepara PK, Siegenfeld AF, Taleb NN, Bar-Yam Y. Unmasking the mask studies: why the effectiveness of surgical masks in preventing respiratory infections has been underestimated. https://arxiv.org/abs/2102.04882.

33. Greenhalgh T, Schmid M, Czypionka T, Bassler D, Gruer L. Face masks for the public during the covid-19 crisis. BMJ. (2020) 369:m1435. doi: 10.1136/bmj.m1435

34. Cartaud A, Quesque F, Coello Y. Wearing a face mask against Covid-19 results in a reduction of social distancing. PLOS ONE. (2020) 15:e0243023. doi: 10.1371/journal.pone.0243023

35. Desai A, Aronoff D. Masks and coronavirus disease 2019 (COVID-19). JAMA. (2020) 323:2103. doi: 10.1001/jama.2020.6437

36. Prather K, Marr L, Schooley R, McDiarmid M, Wilson M, Milton D. Airborne transmission of SARS-CoV-2. Science. (2020) 370:303-4. doi: 10.1126/science.abf0521

37. Marcelo G. Bioaerosol size effect in COVID-19 transmission. Int. J Health Plann Mgmt. (2020) 2020:1-10. doi: 10.20944/preprints202004.0093.v2

38. Stadnytskyi V, Bax C, Bax A, Anfinrud P. The airborne lifetime of small speech droplets and their potential importance in SARS-CoV-2 transmission. Proc Natl Acad Sci USA. (2020) 117:202006874. doi: 10.1073/pnas.2006874117

39. Alonso C, Raynor P, Davies P, Torremorell M. Concentration, size distribution, and infectivity of airborne particles carrying swine viruses. PLoS ONE. (2015) 10:e0135675. doi: 10.1371/journal.pone.0135675

40. Zhu N, Zhang D, WangW, Li X. A novel coronavirus from patients with pneumonia in China, 2019. N Engl J Med. (2020) 382:727-33. doi: 10.1056/NEJMoa2001017

41. Freud E, Stajduhar A, Rosenbaum R, Avidan G, Ganel T. The COVID-19 pandemic masks the way people perceive faces. Sci Rep. (2020) 10:22344. doi: 10.1038/s41598-020-78986-9

42. Adamson LB, Frick JE. The still face: a history of a shared experimental paradigm. Infancy. (2003) 4:451-73. doi: 10.1207/S15327078IN0404_01

43. Paulesu E, Perani D, Blasi V, Silani G, Borghese NA, Giovanni U, et al. A functional-anatomical model for lipreading. J Neurophysiol. (2003) 90:200513. doi: $10.1152 /$ jn.00926.2002

44. Baron R. Mechanisms of human facial recognition. Int J Man-Machine Stud. (1981) 15:137-78. doi: 10.1016/S0020-7373(81)80001-6

45. Marigold D, Patla A. Visual information from the lower visual field is important for walking across multi-surface terrain. Exp Brain Res. (2008) 188:23-31. doi: 10.1007/s00221-008-1335-7 
46. Häkkinen L. Vision in the elderly and its use in the social environment. Scand J Soc Med Suppl. (1984) 35:5-60.

47. Horton J, Fahle M, Mulder T, Trauzettel-Klosinski S. Adaptation, perceptual learning, and plasticity of brain functions. Graefes Arch Clin Exp Ophthalmol. (2017) 255:435-47. doi: 10.1007/s00417-016-3580-y

48. Changizi M, Shimojo S. "X-ray vision" and the evolution of forward-facing eyes. J Theor Biol. (2008) 254:756-67. doi: 10.1016/j.jtbi.2008.07.011

49. Young S, Smith M, Tatham A. Visual field artifacts from face mask use. $J$ Glaucoma. (2020) 29:989-91. doi: 10.1097/IJG.0000000000001605

50. WHO. Falls. World Health Organisation (2018). Available online at: https:// www.who.int/news-room/fact-sheets/detail/falls.

51. Changizi M, Barber T. EXPRESSLY HUMAN: Decoding the Language of Emotion. (2022).

52. Nestor M, Fischer D, Arnold D. "Masking” our emotions: botulinum toxin, facial expression and well-being in the age of COVID-19. J Cosmet Dermatol. (2020) 19:2154-60. doi: 10.1111/jocd.13569

53. Carbon C-C. Wearing face masks strongly confuses counterparts in reading emotions. Front Psychol. (2020) 11:566886. doi: 10.3389/fpsyg.2020. 566886

54. Bandaru S, Augustine A, Lepcha A, Sebastian S, Gowri M, Philip A, et al. The effects of N95 mask and face shield on speech perception among healthcare workers in the coronavirus disease 2019 pandemic scenario. J Laryngol Otol. (2020) 28:1-10. doi: 10.1017/S0022215120 002108

55. Wong C, Yip B, Mercer S, Griffiths S, Kung K, Wong $M$, et al. Effect of facemasks on empathy and relational continuity: a randomised controlled trial in primary care. BMC Family Pract. (2013) 14:200. doi: 10.1186/1471-2296-14-200

56. Goldin A, Weinstein B, Shiman N. How do medical masks degrade speech reception?. Hear Rev. (2020) 27:8-9.

57. Ujiie Y, Asai T, Wakabayashi A. Individual differences and the effect of face configuration information in the McGurk effect. Exp Brain Res. (2018) 236:973-84. doi: 10.1007/s00221-018-5188-4

58. Perna G, Cuniberti F, Daccò S, Maria N, Caldirola D. Impact of respiratory protective devices on respiration: implications for panic vulnerability during the COVID-19 pandemic. J Affect Disord. (2020) 277:772-8. doi: 10.1016/j.jad.2020.09.015

59. Xie Z, Yang Y, Zhang H. Mask-induced contact dermatitis in handling COVID-19 outbreak. Contact Dermatitis. (2020) 83:166-7. doi: $10.1111 / \operatorname{cod} .13599$

60. Szepietowski J, Matusiak L, Szepietowska M, Krajewski P, Białynicki-Birula R. Face mask-induced itch: a self-questionnaire study of 2,315 responders during the COVID-19 pandemic. Acta Derm Venereol. (2020) 100:adv00152. doi: 10.2340/00015555-3536

61. Hu K, Fan J, Li X, Gou X, Li X, Zhou X. The adverse skin reactions of health care workers using personal protective equipment for COVID-19. Medicine. (2020) 99:e20603. doi: 10.1097/MD.0000000000020603

62. Foo CCI, Goon ATJ, Leow YH, Goh CL. Adverse skin reactions to personal protective equipment against severe acute respiratory syndromea descriptive study in Singapore. Contact Dermatitis. (2006) 55:291-4. doi: 10.1111/j.1600-0536.2006.00953.x
63. Hua W, Zuo Y, Wan R, Xiong L, Tnag J, Zou L, et al. Short-term skin reactions following use of N95 respirators and medical masks. Contact Dermatitis. (2020) 83:115-21. doi: 10.1111/cod.13601

64. Gefen A. Skin Tears, Medical Face Masks, and Coronavirus. Tel-Aviv: Wound Management \& Prevention (2020).

65. Fikenzer S, Uhe T, Lavall D, Rudolph U, Falz R, Busse M, et al. Effects of surgical and FFP2/N95 face masks on cardiopulmonary exercise capacity. Clin Res Cardiol. (2020) 109:1522-30. doi: 10.1007/s00392-020-01704-y

66. Butz U. Rückatmung von Kohlendioxid bei Verwendung von Operationsmasken als Hygienischer Mundschutz an Medizinischem Fachpersonal. [Doktors der Medizin]: Institut für Anaesthesiologie der Technischen Universität München (2004). Available online at: https://mediatum.ub.tum.de/doc/602557/602557. pdf.

67. Kainth G. Novel tip to prevent ear irritation with surgical face masks (FRSM) during the coronavirus (COVID-19) pandemic. Ann R Coll Surg Engl. (2020) 102:1-2. doi: 10.1308/rcsann.2020.0143

68. World Health Organisation. People Should NOT Wear Masks While Exercising. (2020). Available online at: https://www.youtube.com/watch?v=1_ AxGswGnno\&feature=emb_title.

69. Kim E, Kim Y, Park J, Jung J, Lee J, Kim H. Evaluation of the prognosis of COVID-19 patients according to the presence of underlying diseases and drug treatment. Int J Environ Res Public Health. (2021) 18:5342. doi: 10.3390/ijerph18105342

70. Demertzis K, Tsiotas D, Magafas L. Modeling and forecasting the COVID19 temporal spread in Greece: an exploratory approach based on complex network defined splines. Int J Environ Res Public Health. (2020) 17:4693. doi: 10.3390/ijerph17134693

71. Aprato A, Guindani N, Massè A, Castelli CC, Cipolla A, Antognazza D, et al. Clinical activities, contaminations of surgeons and cooperation with health authorities in 14 orthopedic departments in north italy during the most acute phase of Covid-19 pandemic. Int J Environ Res Public Health. (2021) 18:5340. doi: 10.3390/ijerph18105340

Conflict of Interest: The authors declare that the research was conducted in the absence of any commercial or financial relationships that could be construed as a potential conflict of interest.

Publisher's Note: All claims expressed in this article are solely those of the authors and do not necessarily represent those of their affiliated organizations, or those of the publisher, the editors and the reviewers. Any product that may be evaluated in this article, or claim that may be made by its manufacturer, is not guaranteed or endorsed by the publisher.

Copyright (C) 2021 Lansiaux, Tchagaspanian, Arnaud, Durand, Changizi and Forget. This is an open-access article distributed under the terms of the Creative Commons Attribution License (CC BY). The use, distribution or reproduction in other forums is permitted, provided the original author(s) and the copyright owner(s) are credited and that the original publication in this journal is cited, in accordance with accepted academic practice. No use, distribution or reproduction is permitted which does not comply with these terms. 